\title{
Original
}

\section{Fracture strength of ceramic monolithic crown systems of different thickness}

\author{
Niklas Nordahl, Per Vult von Steyern, and Christel Larsson \\ Department of Materials Science and Technology, Faculty of Odontology, Malmö University, Malmö, Sweden \\ (Received February 18, 2015; Accepted June 2, 2015)
}

\begin{abstract}
The objective of this study was to evaluate fracture strength of high-translucent (HTZ) and low-translucent (LTZ) zirconia and glass-ceramic (LDS) crowns. HTZ and LTZ crowns were made with thicknesses of; $0.3 \mathrm{~mm}, 0.5 \mathrm{~mm}, 0.7 \mathrm{~mm}, 1.0$ $\mathrm{mm}$, and $1.5 \mathrm{~mm}$; and LDS crowns of $1.0 \mathrm{~mm}$ and 1.5 mm thicknesses. Each group consisted of 10 crowns. All crowns underwent artificial aging before loading until fracture. Mean fracture strengths varied from $450 \mathrm{~N}$ to $3,248 \mathrm{~N}$ in the LTZ group, $438 \mathrm{~N}$ to 3,487 $\mathrm{N}$ in the HTZ group, and 1,030 $\mathrm{N}$ to $1,431 \mathrm{~N}$ in the LDS group. The load at fracture of HTZ and LTZ crowns was equal. The load at fracture of yttriastabilized tetragonal zirconia polycrystals crowns was significantly greater than LDS crowns $(P=\mathbf{0 . 0 0 0})$. Two types of fractures were recorded; complete and partial crack-like fracture. The crack type fracture occurred most frequently in all groups except in the thicker LTZ groups (1.0 $\mathrm{mm}$ and $1.5 \mathrm{~mm})$. According to this study, there is no difference in strength between crowns made of high-translucent or low-translucent zirconia. At equal thickness, the strength of zirconia crowns was significantly greater than that of lithiumdisilicate glass-ceramic. (J Oral Sci 57, 255-261, 2015)
\end{abstract}

Keywords: zirconia; lithium-disilicate; crowns; translucent; Y-TZP.

Correspondence to Dr. Christel Larsson, Avdelningen för Materialvetenskap och Teknologi, Odontologiska fakulteten, Malmö Högskola, 20506 Malmö, Sweden

Fax:+46-40-6658521 E-mail: christel.larsson@mah.se

doi.org/10.2334/josnusd.57.255

DN/JST.JSTAGE/josnusd/57.255

\section{Introduction}

All-ceramic crowns are increasingly popular due to their excellent aesthetics and biocompatibility and acceptable strength (1). Of the all-ceramic materials available today, yttria-stabilized tetragonal zirconia polycrystals (Y-TZP) exhibit the greatest fracture strength and are comparable to the gold standard in dental crown restorations thus far, metal-ceramic crowns based on high-noble alloy (1). Crowns made of Y-TZP have been used for both anterior and posterior restorations. Although the strength of the core material in Y-TZP crowns is excellent and the survival rates are high, clinical trials report fractures of the veneering material, which lowers the success rates (2).

The veneering material thus becomes a weak link for a restoration, and has been excluded, in so-called monolithic crowns. Monolithic crowns made of glass-ceramics based on lithium-disilicate have shown improved strength compared to earlier glass-ceramics and been suggested to be used for both anterior and posterior restorations (3). Few clinical trials have been conducted, but show promising results (4-6).

The aesthetic properties of lithium-disilicate glass ceramic materials are high enough to avoid the use of a veneering material. This was previously not an alternative for Y-TZP restorations as this material is less translucent and only available in opaque white color. Recently however, Y-TZP materials with improved translucency and color options have been introduced (7) making the monolithic Y-TZP restoration a possible treatment option.

The toughness of Y-TZP is dependent on the phasetransformation ability. This is achieved by adding dopants, e.g. 3 mol\% yttria. At an optimal grain size, the tetragonal grains can expand at the crack tip and trans- 
Table 1 Material properties according to the manufacturers

\begin{tabular}{|c|c|c|c|c|}
\hline Material & Manufacturer & E-Modulus (GPa) & Strength $(\mathrm{MPa})$ & Toughness $\left(\mathrm{MPa} \mathrm{m}{ }^{1 / 2}\right)$ \\
\hline Lava Zirconia & 3M ESPE & $210^{\mathrm{a}}$ & $>1,100^{\mathrm{b}}$ & $5-10^{c}$ \\
\hline Lava Plus & 3M ESPE & $210^{\mathrm{a}}$ & $>1,100^{\mathrm{b}}$ & $5-10^{\mathrm{c}}$ \\
\hline IPS e.max CAD & Ivoclar Vivadent & $95 \pm 5$ & $360 \pm 60^{d}$ & $2.0-2.5^{\mathrm{e}}$ \\
\hline \multicolumn{5}{|c|}{$\begin{array}{l}\text { a Data colletcted from: Lava Plus technical product profile; 3M ESPE Deutchland GmbH } 2012 \text { and IPS e.max CAD Scientific } \\
\text { Documentation, Ivoclar Vivadent AG; Liechtenstein } 2011 \\
\text { b Flexural strength (Punch Test, ISO 6872) } \\
\text { c Fracture toughness (KIC SEVNB, ISO 6872 Annex) } \\
\text { d Biaxial strength (ISO 6872) } \\
{ }^{\text {e }} \text { Fracture toughness (SEVNB) }\end{array}$} \\
\hline
\end{tabular}
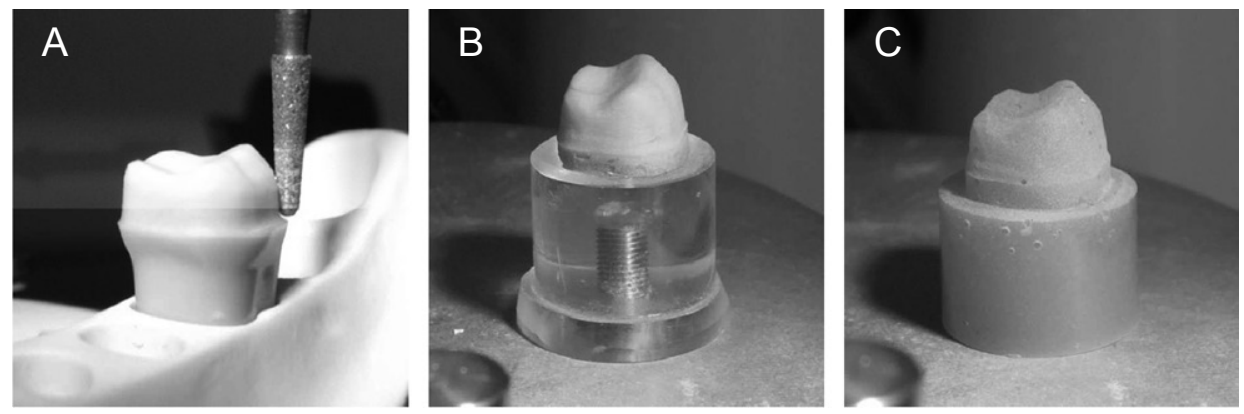

Fig. 1 A) Tooth preparation in parallellometer. B) Master die; replica of a first mandibular molar (tooth 36) fit onto a plexi-glass cylinder. C) Reinforced epoxy resin abutment.

form to a monoclinic, stable phase and prevent cracks from developing (1). To enhance the translucency of Y-TZP, some manufacturers have altered the grain size and/or added other dopants, e.g. alumina. This could affect the mechanical properties of the new material. However, few studies have analyzed possible differences in strength between high-translucent and low-translucent Y-TZP, and even fewer have compared these materials with glass-ceramics $(8,9)$.

Monolithic crowns offer other advantages such as reduced production time and improved cost-effectiveness (9). Crown preparation always involves a risk, causing preparation trauma to the vital tooth, a risk that is increased the more extensive the preparation is (10). Eliminating the veneering material in monolithic crowns creates possibilities for more minimally invasive preparations and restorations.

Restorations made from Y-TZP materials can likely be made thinner than glass-ceramic restorations as the strength of Y-TZP exceeds that of glass-ceramics. There is, however, no consensus on how thin the copings can be made and information is lacking on to what extent decreasing the thickness of monolithic Y-TZP and glass ceramic crowns affects fracture strength.

The aim of the present study was therefore to compare the fracture strength of high-translucent Y-TZP and lowtranslucent Y-TZP and lithium-disilicate glass ceramic crowns with varying thickness.
The hypotheses were:

- The fracture strength of high-translucent Y-TZP crowns would be lower than the fracture strength of low-translucent Y-TZP crowns.

- The fracture strength of Y-TZP crowns would be greater than the fracture strength of lithium-disilicate glass ceramic crowns of equal thickness.

\section{Materials and Methods}

One hundred and twenty monolithic crowns were made with varying thicknesses. Fifty crowns were made from low-translucent Y-TZP (LTZ) (Lava Zirconia, 3M ESPE, Seefeld, Germany), 50 crowns from high-translucent Y-TZP (HTZ) (Lava Plus, 3M ESPE) and 20 crowns from lithium-disilicate glass ceramic (LDS) (IPS e.max CAD, Ivoclar-Vivadent AG, Schaan, Liechtenstein) (Table 1).

\section{Tooth preparation and die fabrication}

A tooth replica of the first mandibular molar (tooth 36) made from composite material (KaVo Dental $\mathrm{GmbH}$, Biberach/Riß, Germany) was prepared to receive a full anatomic crown using a chamfer diamond bur (268.10C “Two Striper", Abrasive Technology, Lewis Center, $\mathrm{OH}$, USA). The convergence angle between the two axial walls was designed with a $10^{\circ}$ taper. The preparation was made with an occlusal reduction of approximately $1 \mathrm{~mm}$ and a shallow circumferential chamfer of approximately $0.7 \mathrm{~mm}$. The angles were rounded according to the manu- 
facturer's instructions to reduce stress concentration and reduce the need for drill compensation in the milling process (Fig. 1A). A master die was fabricated by cutting the prepared tooth model $2 \mathrm{~mm}$ below the preparation margin and fitting it on a $14 \mathrm{~mm}$ diameter plexi glass cylinder (Plexlite, Plastprodukter AB, Malmö, Sweden). Undercuts were blocked out using blue wax (THOWAX, sculpting wax, blue, YETI Dental Produkte GmbH, Engen, Germany) (Fig. 1B).

Ten impressions of the master die were made using a low viscosity lab silicone impression material (Dublicil 15, Dreve Dentamid GmbH, Unna, Germany). The impressions were poured with an epoxy resin (EpoFix, Struers, Ballerup, Denmark) reinforced with $40 \% \mathrm{SiO}_{2}$ powder filling (Fig. 1C). Each impression was poured 12 times producing a total of 120 abutments. The abutments were randomized between the different groups of crowns.

\section{Crown fabrication}

The master die was scanned using a lab scanner (3Shape D700, 3Shape A/S, Copenhagen, Denmark) and imported into a CAD-based design application (3Shape Dental Designer, 3Shape A/S) where five different crowns were designed with varying thicknesses: $0.3 \mathrm{~mm}, 0.5 \mathrm{~mm}, 0.7$ $\mathrm{mm}, 1.0 \mathrm{~mm}$, and $1.5 \mathrm{~mm}$ (Fig. 2).

\section{LavaZirconia (LTZ) and LavaPlus (HTZ) groups:}

Die interface parameters were set to match the settings recommended by the manufacturer with a cement gap of $25 \mu \mathrm{m}$ and distance to the margin line of $0.3 \mathrm{~mm}$. A total of 10 groups each containing 10 crowns were made from the two zirconia materials i.e. $50 \mathrm{LTZ}$ and $50 \mathrm{HTZ}$. The crowns were made with uniform thicknesses varying from $0.3 \mathrm{~mm}, 0.5 \mathrm{~mm}, 0.7 \mathrm{~mm}, 1.0 \mathrm{~mm}$, and $1.5 \mathrm{~mm}$. The cervical thickness of all crowns was $0.3 \mathrm{~mm}$.

CAM-files were exported as ULDC-files and sent to a Lava Milling Centre for production (Lundbergs Tandtekniska Laboratorium, Umeå, Sweden). After milling in a pre-sintered stage, the crowns were dyed with dyeing liquid (Lava Plus High Translucency Zirconia Dyeing Liquid - A3, 3M ESPE) and sintered, all according to the manufacturer's instructions. Subsequent polishing of the external surfaces was done with brushes (Robinson's Bristle Brushes, soft no.9, Buffalo Dental Manufacturing Co, Syosset, NY, USA) and polishing paste (Zircon-Brite polishing paste, DVA Inc, Corona, CA, USA). The inner surfaces were sandblasted with 50 $\mu \mathrm{m} \mathrm{Al}_{2} \mathrm{O}_{3}$ at $0.2 \mathrm{MPa}$ pressure (Zhermack SpA, Rovigno, Italy) and cleaned in an ultrasonic bath for $3 \mathrm{~min}$ at 42 $\mathrm{Hz}$ (Ultrasonic Cleaner CD-4800, Sharpertek, Pontiac, MI, USA).

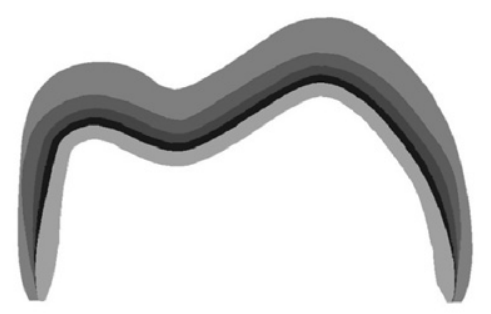

Fig. 2 Crown profile/thickness in bucco-lingual cross section. Ranging from inner to outer: 0.3 $\mathrm{mm}, 0.5 \mathrm{~mm}, 0.7 \mathrm{~mm}, 1.0 \mathrm{~mm}$, and $1.5 \mathrm{~mm}$.

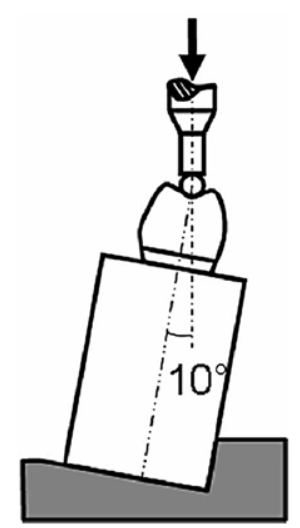

Fig. 3 Schematic illustration of the test set-up for pre-load and load until fracture.

IPS e.max CAD (LDS) groups:

Two groups of ten crowns were made. The groups were made with the same design as the $1.0 \mathrm{~mm}$ and $1.5 \mathrm{~mm}$ LTZ and HTZ crowns. CAM-files were sent to a milling centre for production (Dental Syd, Malmö, Sweden). After milling, the crowns were crystallized and glazed according to the manufacturer's recommendations. The inner surfaces were etched with $5 \%$ hydrofluoric acid (IPS Ceramic Etching Gel, Ivoclar-Vivadent AG).

\section{Thermocycling}

All crowns underwent 5,000 cycles (thermocycling device, LTC 100, LAM Technologies, Florence, Italy) between two water baths, $5^{\circ} \mathrm{C}$ and $55^{\circ} \mathrm{C}$. Each cycle lasted $60 \mathrm{~s} ; 20 \mathrm{~s}$ in each bath and $10 \mathrm{~s}$ for transfer between the baths.

\section{Cementation}

The resin abutments were sandblasted with $125 \mu \mathrm{m} \mathrm{Al}_{2} \mathrm{O}_{3}$ at two bars pressure and $5 \mathrm{~cm}$ distance at a $90^{\circ}$ angle. Abutments and crowns were cleaned in an ultrasonic bath for $5 \mathrm{~min}$ and rubbed with $95 \%$ ethanol.

The HTZ and LTZ groups were cemented using RelyX Unicem (3M ESPE) and the LDS groups were cemented 
Table 2 Load at fracture for each specimen (N)

\begin{tabular}{|c|c|c|c|c|c|c|c|c|c|c|c|c|}
\hline \multirow{2}{*}{$\begin{array}{l}\text { Material/ } \\
\text { Thickness (mm) } \\
\text { Specimen }\end{array}$} & \multicolumn{5}{|c|}{ LTZ (Lava Zirconia) } & \multicolumn{5}{|c|}{ HTZ (Lava Plus) } & \multicolumn{2}{|c|}{$\begin{array}{c}\text { LDS } \\
\text { (IPS e.max CAD) }\end{array}$} \\
\hline & 0.3 & 0.5 & 0.7 & 1.0 & 1.5 & 0.3 & 0.5 & 0.7 & 1.0 & 1.5 & 1.0 & 1.5 \\
\hline 1 & 453 & 550 & 1,373 & 2,525 & 3,685 & 433 & 987 & 1,287 & 2,089 & 3,705 & 1,559 & 1,424 \\
\hline 2 & 471 & 625 & 1,321 & 2,675 & 3,593 & 300 & 844 & 914 & 1,860 & 3,040 & 731 & 1,250 \\
\hline 3 & 190 & 971 & 1,375 & 1,611 & 3,115 & 448 & 924 & 1,169 & 1,909 & 3,313 & 1,664 & 1,349 \\
\hline 4 & 575 & 839 & 783 & 2,409 & 3,601 & 310 & 925 & 1,336 & 2,088 & 3,322 & 825 & 1,283 \\
\hline 5 & 455 & 913 & 1,411 & 2,489 & 2,560 & 386 & 995 & 927 & 1,843 & 3,816 & 652 & 1,575 \\
\hline 6 & 457 & 810 & 1,280 & 2,187 & 2,252 & 422 & 1,083 & 1,302 & 1,746 & 3,160 & 688 & 1,307 \\
\hline 7 & 447 & 792 & 1,241 & 2,177 & 3,632 & 453 & 911 & 1,299 & 2,030 & 3,570 & 723 & 1,985 \\
\hline 8 & 489 & 760 & 1,203 & 1,778 & 3,338 & 414 & 860 & 1,554 & 2,213 & 4,644 & 2,066 & 1,360 \\
\hline 9 & 527 & 979 & 1,266 & 1,861 & 3,501 & 710 & 888 & 1,274 & 1,617 & 3,016 & 755 & 1,205 \\
\hline 10 & 434 & 630 & 969 & 2,087 & 3,565 & 502 & 741 & 899 & 2,165 & 3,285 & 634 & 1,575 \\
\hline Mean & $450^{\mathrm{ac}}$ & $787^{\mathrm{a}}$ & $1,222^{\mathrm{d}}$ & $2,180^{\mathrm{e}}$ & $3,284^{\mathrm{f}}$ & $438^{\mathrm{c}}$ & $916^{\mathrm{b}}$ & $1,196^{\text {bd }}$ & $1,956^{\mathrm{e}}$ & $3,487^{\mathrm{f}}$ & 1,030 & 1,431 \\
\hline Std. Deviation & 101 & 148 & 198 & 351 & 497 & 114 & 94 & 217 & 193 & 486 & 524 & 231 \\
\hline $\begin{array}{l}\text { Fracture mode } \\
\text { (crack/complete) }\end{array}$ & $10 / 0$ & $7 / 3$ & $9 / 1$ & $2 / 8$ & $4 / 6$ & $9 / 1$ & $10 / 0$ & $10 / 0$ & $8 / 2$ & $6 / 4$ & $7 / 3$ & $6 / 4$ \\
\hline
\end{tabular}

abcdef Groups denoted with the same superscripted letter indicate no statistical significant difference in load at fracture $(P>0.05)$ between the groups.

using Multilink Implant (Ivoclar-Vivadent AG) according to the respective manufacturer's protocols. Excess cement was removed using a brush. The cement was light cured from three directions, $20 \mathrm{~s}$ each, with a light curing lamp (Elipar S2, 3M ESPE).

During polymerization of the cement, the specimens were fixed in a jig with a constant occlusal load of $15 \mathrm{~N}$. After cementation, the specimens were stored for 24-48 $h$ in a sealed plastic container with a thin layer of water to prevent drying of the cement.

\section{Preload}

All specimens were subjected to cyclic preload: 10,000 cycles with loads between $30-300 \mathrm{~N}$ at $1 \mathrm{~Hz}$ in a preload device (MTI Engineering AB, Lund/Pamaco AB, Malmö, Sweden). Preload was performed with the specimens submerged in water and load was applied with a $2.5 \mathrm{~mm}$ stainless steel ball placed on the occlusal surface of the crowns, mounted at a $10^{\circ}$ angle (Fig. 3).

\section{Load to fracture}

All specimens were loaded to fracture in a static loading device (Instron, Instron Co. Ltd., Norwood, MA, USA). The load was applied with a $2.5 \mathrm{~mm}$ stainless steel ball placed on the occlusal surface of the crowns, mounted at a $10^{\circ}$ angle. The speed of the cylinder was $0.255 \mathrm{~mm} /$ min. A thin plastic foil (PE-Baufolie, Probau, Mannheim, Germany) was inserted between the crown and the ball.

The load at fracture was registered. Fracture was defined as a visible crack in combination with a load drop or an acoustic event, whichever came first. Photographs of the specimens were taken under a light microscope (Wild M3, Wild Heerbrugg, Heerbrugg Switzerland) at

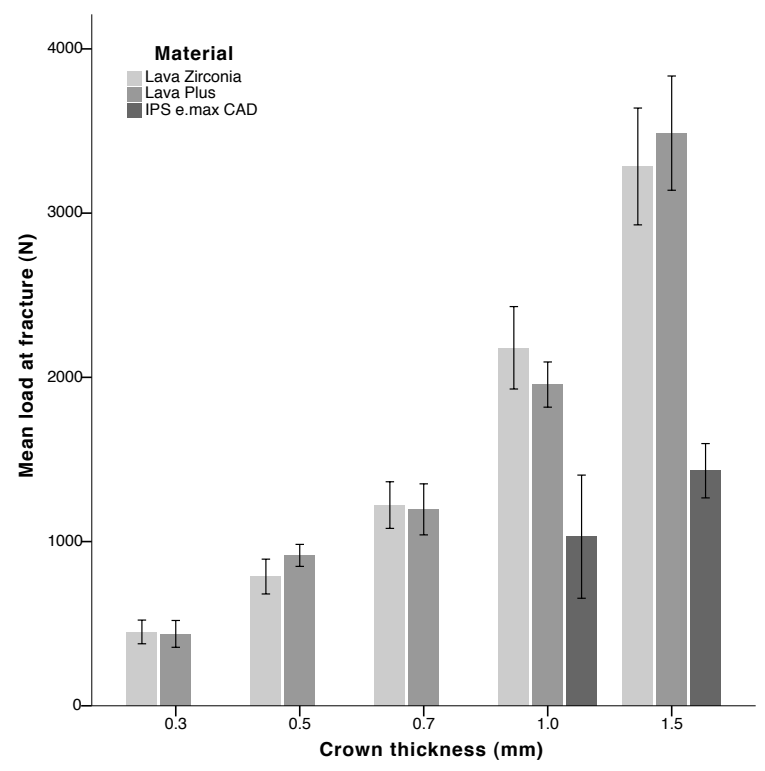

Fig. 4 Column chart of loads at fracture.

$8 \times$ magnification. Fracture mode was defined as crack or complete fracture.

\section{Statistical analysis}

The results were analyzed using one-way ANOVA and Tukey's Post Hoc Test using IBM SPSS Statistics for Macintosh, Version 22.0 (IBM Corp, Armonk, NY, USA). Results were considered statistically significant at a $P$-value $<0.05$.

\section{Results}

The load at fracture decreased from thicker to thinner within the same material for all groups. The differences were statistically significant for all groups $(P<0.017)$ 

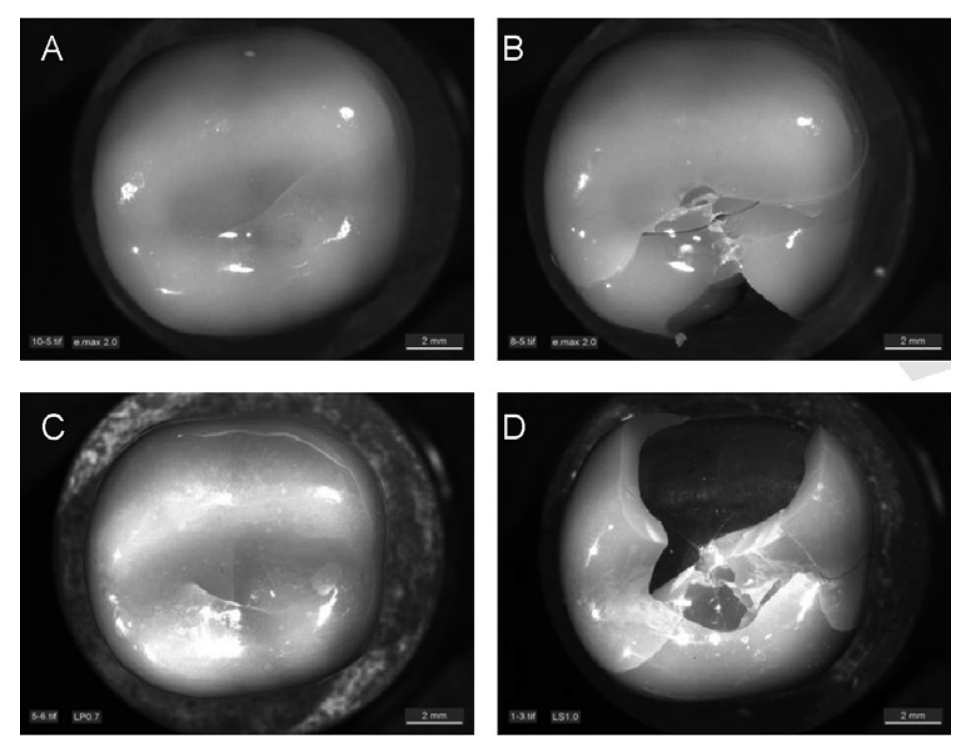

Fig. 5 Fracture mode after load to fracture of monolithic glass-ceramic crowns; crack (A) and complete fracture (B), and monolithic zirconia crowns; crack (C) and complete fracture (D).

except for LTZ $0.3 \mathrm{~mm}$ and $0.5 \mathrm{~mm}(P=0.101)$ and HTZ $0.5 \mathrm{~mm}$ and $0.7 \mathrm{~mm} .(P=0.136)$.

The load at fracture of HTZ was equal to that of LTZ except for $0.5 \mathrm{~mm}$ thickness where HTZ showed higher load at fracture values $(P=0.032)$.

The load at fracture of Y-TZP crowns (LTZ and HTZ) was significantly greater than LDS crowns $(P=0.000)$ (Table 2, Fig. 4).

Two types of fracture were recorded: partial crack-like and complete fractures through the crown (Fig. 5 A-D). For the LTZ group, crack type fractures dominated, although for the thicker crowns $(1.0 \mathrm{~mm}$ and $1.5 \mathrm{~mm})$ the majority of the fractures were complete. For the HTZ and LDS groups, the crack type fractures were predominant irrespective of crown thickness.

\section{Discussion}

The high- and low-translucent zirconia crowns performed equally well. The first hypothesis was thus rejected. Proposed concerns that manipulation of grain size and change of dopants may affect the mechanical properties of high-translucent zirconia were thus dismissed in the present study. All Y-TZP crowns showed significantly higher fracture strength compared to LDS crowns, thus confirming the second hypothesis. Considering the differences in structure and properties of these two materials, this outcome was expected. LDS materials do not possess the same fracture toughness as Y-TZP materials with their unique ability for phase transformation to counter crack propagation.

Reducing the dimensions of a restoration will reduce its strength (11). The results in the present study showed, as expected, that the strength increased with increasing crown thickness for all groups. The main purpose of the study was not to corroborate this fact but rather to investigate the relationship between strength and changes in thickness of monolithic crowns and to compare the three included materials that are considered to be suitable for crowns within the same field of indications.

The choice of crown thickness was made by taking into consideration the recommendations of the respective manufacturers. In addition, a group of $0.3 \mathrm{~mm}$ crowns, which is less than recommended, and crowns with increased thickness (e.g. $1.5 \mathrm{~mm}$ ), were included to test limits and make comparisons.

An anatomical shape of crowns was chosen to ensure an in-vitro setup, mimicking the clinical situation as far as possible. One mm occlusal reduction was done to be able to use the same die shape and size throughout and accommodate the gradually increasing thickness of crowns. Another way would be to gradually reduce the dimension of the dies for each increase in crown dimension. This leads to a reduced die for the thicker crowns which might lead to reduced support as well as differences in Hoop stress between groups as Hoop stress is diameter dependent.

In addition, an abutment material with tooth-like properties was chosen. By using an epoxy material saturated with silica powder, two objectives were fulfilled: the die strength increased and conditions for a chemical bond between the silica component in the die material and the adhesive cement system could be created. Microme- 
chanical retention was achieved by sandblasting the die prior to cementation. The modulus of elasticity of the die material (4.7-4.9 GPa) was close to that of dentine (8.7 to $11.2 \mathrm{GPa})(12)$ compared to other materials used for dies, e.g. aluminium (69 GPa) or resin (2-3 GPa) (13).

All specimens irrespective of material were treated in the same manner except for the choice of cement that was based on the manufacturer's recommendations. Studies have shown that the choice of cement is not important for the strength of Y-TZP restorations since the material is intrinsically strong enough and does not require further reinforcement by any particular cement (14). A resin-based cement was chosen as studies have found less occurrence of loss of retention in Y-TZP restorations cemented with adhesive cements (15). The IPS e.max CAD material is more susceptible to stress-corrosion depending on the high glass content in the material (1). These restorations benefit from reinforcement by adhesive cement and consequently such a cement, recommended by the manufacturer, was used for the LDS groups.

Several studies have shown a significant decrease in load at fracture in specimens subjected to artificial aging procedures (16-18). In this study, 5,000 cycles in a thermocycling device were used which has been suggested to represent half a year of in vivo use and 10,000 cycles of preload (16). Thermocycling was performed prior to cementation, which could be disputed as the procedure has predominantly been argued to affect the cement. The objective of the present study was not, however, to evaluate cement bond strength and possible debonding during loading, but rather to evaluate the influence of water on the strength of different ceramics, as presence of water has been suggested to weaken inter-atomic ceramic bonding as well as cause yttria depletion (1). In this way, all surfaces of the specimens were accessible for potential water-related damage.

Reported loads during normal function vary considerably; there is no accepted consensus on either loads present in vivo or how they should be replicated in vitro. Some authors use lower loads, 100-200 N, others use loads in the range of 500-800 N (17). Kohorst et al (17) concluded that "artificial aging resulted in a significant decrease in load-bearing capacity whereas variation in aging parameters did not show significant influence". In the absence of an accepted consensus, preloading between 30-300 $\mathrm{N}$ was chosen to avoid using either too low or too high loads.

Load to fracture was performed using a $2.5 \mathrm{~mm}$ stainless steel ball. Larger diameter indenters have been suggested to better represent clinical wear facets (19). This may have influenced the results of the present study which must be interpreted accordingly. On the other hand, larger diameter indenters are difficult to place in the fossae of anatomically shaped crowns, instead, the cusps are pressed laterally with failures resulting from cracks initiating in the occlusal fissure. The cross head speed of $0.255 \mathrm{~mm} / \mathrm{min}$ was chosen as this seems sufficient to allow for crack build-up and propagation. This test set-up has been used to examine different ceramic materials in a variety of studies over a long period of time, making comparisons between studies possible (20).

In the present study, there were two types of fractures, crack and complete fracture. In a similar in-vitro study investigating the load bearing capacity of Y-TZP, lithium-disilicate glass ceramic and metal-ceramic crowns, the Y-TZP and lithium-disilicate glass ceramic crowns all failed by complete fracture (21). The specimens in that study did not, however, undergo any artificial aging procedures as in the present study, which might be one explanation for differences in fracture mode. Another difference was that the present study used a $10^{\circ}$ angulated load. The $10^{\circ}$ tilting leads to elements of tensile forces in addition to pure compressive forces and also a slight sliding action, creating more complex stresses. The outcome of the present study may perhaps better represent how crowns react in a clinical situation considering the use of artificial aging, angulated load and complex stresses.

One might hypothesize that there would be differences in fracture mode as well as fracture strength between the Y-TZP and LDS group, considering the differences in material properties. However, significant differences were not shown in the present study, despite numerical differences among some of the thicker LTZ crowns. A possible explanation could lie in the test set-up, or the fact that no power analysis was performed and that more samples are needed to detect possible differences.

The lowest recorded load at fracture within the 1.0 mm crown groups was $634 \mathrm{~N}$ (IPS e.max CAD), and for the Y-TZP groups at thicknesses of $0.5 \mathrm{~mm}$ was 550 N (Lava Zirconia). Compared to the forces measured during mastication and swallowing (approximately 5 to $364 \mathrm{~N})(20)$, our results suggest the possibility to reduce crown thickness when working with monolithic ceramic Y-TZP materials. By minimizing the invasiveness of the preparation, it is possible to save valuable tooth structure.

To directly apply information obtained from in vitro tests to recommendations for clinical performance is not possible as the clinical situation is never fully replicated in laboratory testing (22). This is true for all restorations and materials. Ceramic materials, such as Y-TZP and glass ceramics also show a greater scatter in fracture 
strength compared to other material groups, e.g. metals. This calls for a certain safety factor approach when designing ceramic restorations. This, in combination with the maximum bite force recorded during clenching efforts (approximately 216 to $890 \mathrm{~N}$ ) (20), calls for caution when reducing the crown thickness, especially when approaching the manufacturers set lower limit of $0.5 \mathrm{~mm}$. Much strength can be gained with even a slight increase in thickness, as the present study shows. For example, increasing the thickness from 0.5 to 0.7 $\mathrm{mm}$, still a minimally invasive preparation, leads to an increase in strength of $31 \%$ for the high-translucent and $55 \%$ for the low-translucent Y-TZP crowns.

Within the limitations of this in-vitro study, the following can be concluded: crowns made of high translucent Y-TZP show equal fracture strength compared to crowns made of low translucent Y-TZP, irrespective of thickness, suggesting equal clinical performance.

Both high and low translucent zirconia crowns show higher fracture strength compared to corresponding crowns made of lithium-disilicate glass ceramic material, suggesting improved clinical performance for zirconia crowns. Further clinical studies are needed to confirm these findings.

\section{Acknowledgments}

This study was executed without the influence of any third party or manufacturer. Materials and manufacturing were, however, kindly provided by $3 \mathrm{M}$ ESPE Europe, Ivoclar Vivadent Europe, Lundbergs Tandtekniska Laboratorium, Umeå, Sweden and Dental Syd, Malmö, Sweden.

\section{References}

1. Rekow ED, Silva NR, Coelho PG, Zhang Y, Guess P, Thompson VP (2011) Performance of dental ceramics: challenges for improvements. J Dent Res 90, 937-952.

2. Monaco C, Caldari M, Scotti R (2013) Clinical evaluation of 1,132 zirconia-based single crowns: a retrospective cohort study from the AIOP clinical research group. Int J Prosthodont 26, 435-442.

3. Guess PC, Schultheis S, Bonfante EA, Coelho PG, Ferencz JL, Silva NR (2011) All-ceramic systems: laboratory and clinical performance. Dent Clin North Am 55, 333-352.

4. Etman MK, Woolford MJ (2010) Three-year clinical evaluation of two ceramic crown systems: a preliminary study. J Prosthet Dent 103, 80-90.

5. Esquivel-Upshaw J, Rose W, Oliveira E, Yang M, Clark AE, Anusavice K (2013) Randomized, controlled clinical trial of bilayer ceramic and metal-ceramic crown performance. J Prosthodont 22, 166-173.

6. Gehrt M, Wolfart S, Rafai N, Reich S, Edelhoff D (2013) Clinical results of lithium-disilicate crowns after up to 9 years of service. Clin Oral Investig 17, 275-284.

7. Wang F, Takahashi H, Iwasaki N (2013) Translucency of dental ceramics with different thicknesses. J Prosthet Dent 110, 14-20.

8. Zhang Y, Lee JJ, Srikanth R, Lawn BR (2013) Edge chipping and flexural resistance of monolithic ceramics. Dent Mater 29, 1201-1208.

9. Johansson C, Kmet G, Rivera J, Larsson C, Vult von Steyern P (2014) Fracture strength of monolithic all-ceramic crowns made of high translucent yttrium oxide-stabilized zirconium dioxide compared to porcelain-veneered crowns and lithium disilicate crowns. Acta Odontol Scand 72, 145-153.

10. Mjör IA (2001) Pulp-dentin biology in restorative dentistry. Part 2: initial reactions to preparation of teeth for restorative procedures. Quintessence Int 32, 537-551.

11. Ambré MJ, Aschan F, Vult von Steyern P (2013) Fracture strength of yttria-stabilized zirconium-dioxide (Y-TZP) fixed dental prostheses (FDPs) with different abutment core thicknesses and connector dimensions. J Prosthodont 22, 377-382.

12. Meredith N, Sherriff M, Setchell DJ, Swanson SA (1996) Measurement of the microhardness and Young's modulus of human enamel and dentine using an indentation technique. Arch Oral Biol 41, 539-545.

13. Mahmood DJ, Linderoth EH, Vult von Steyern P (2011) The influence of support properties and complexity on fracture strength and fracture mode of all-ceramic fixed dental prostheses. Acta Odontol Scand 69, 229-237.

14. Vult von Steyern P, Ebbesson S, Holmgren J, Haag P, Nilner K (2006) Fracture strength of two oxide ceramic crown systems after cyclic pre-loading and thermocycling. J Oral Rehabil 33, 682-689.

15. Kern M (2015) Bonding to oxide ceramics--laboratory testing versus clinical outcome. Dent Mater 31, 8-14.

16. Gale MS, Darvell BW (1999) Thermal cycling procedures for laboratory testing of dental restorations. J Dent 27, 89-99.

17. Kohorst P, Dittmer MP, Borchers L, Stiesch-Scholz M (2008) Influence of cyclic fatigue in water on the load-bearing capacity of dental bridges made of zirconia. Acta Biomater 4, 1440-1447.

18. Ghazy MH, Madina MM, Aboushelib MN (2012) Influence of fabrication techniques and artificial aging on the fracture resistance of different cantilever zirconia fixed dental prostheses. J Adhes Dent 14, 161-166.

19. Kelly JR (1999) Clinically relevant approach to failure testing of all-ceramic restorations. J Prosthet Dent 81, 652-661.

20. Yoshinari M, Dérand T (1994) Fracture strength of allceramic crowns. Int J Prosthodont 7, 329-338.

21. Sun T, Zhou S, Lai R, Liu R, Ma S, Zhou Z et al. (2014) Loadbearing capacity and the recommended thickness of dental monolithic zirconia single crowns. J Mech Behav Biomed Mater 35, 93-101.

22. Anusavice KJ, Kakar K, Ferree N (2007) Which mechanical and physical testing methods are relevant for predicting the clinical performance of ceramic-based dental prostheses? Clin Oral Implants Res 18, 218-231. 